\title{
Pharmacokinetic Parameter Test
}

National Cancer Institute

\section{Source}

National Cancer Institute. Pharmacokinetic Parameter Test. NCI Thesaurus. Code C87988.

A character or string that represents a pharmacokinetic parameter examination. 